\title{
Weight loss-induced changes in adipose tissue proteins associated with fatty acid and glucose metabolism correlate with adaptations in energy expenditure
}

\author{
Stefan G. J. A. Camps', Sanne P. M. Verhoef, Nadia Roumans, Freek G. Bouwman, Edwin C. M. Mariman \\ and Klaas R. Westerterp
}

\begin{abstract}
Background: Energy restriction causes adaptations in energy expenditure (total-,TEE; resting-,REE; activity induced-,AEE).

Objective: To determine if changes in the levels of proteins involved in adipocyte glucose and fatty acid metabolism as indicators for energy deficiency are related to adaptations in energy expenditure during weight loss.

Methods: Forty-eight healthy subjects (18 men, 30 women), mean \pm SD age $42 \pm 8$ y and BMl $31.4 \pm 2.8 \mathrm{~kg} / \mathrm{m}^{2}$, followed a very low energy diet for 8 wk. Protein levels of fatty acid binding protein 4 (FABP4), fructosebisphosphate aldolase C (AldoC) and short chain 3-hydroxyacyl-CoA dehydrogenase (HADHsc) (adipose tissue biopsy, western blot), TEE (doubly labeled water), REE (ventilated hood), and AEE were assessed before and after the 8-wk diet.
\end{abstract}

Results: There was a positive correlation between the decrease in AldoC and the decrease in TEE $(R=0.438, P<0.01)$ and the decrease change in $\mathrm{AEE}(R=0.439, P<0.01)$. Furthermore, there was a negative correlation between the increases in HADHsc and the decrease in REE $(R=0.343, P<0.05)$.

Conclusion: The decrease in AldoC correlated with the decrease in $\mathrm{AEE}$, which may be explained by a decreased glycolytic flux. Additionally, the change in HADHsc, a crucial enzyme for a step in beta-oxidation, correlated with the adaptation in REE.

Trial registration: Clinical Trial Registration Number: NCT01015508 at clinicaltrials.gov

Keywords: Energy expenditure, Physical activity, Body composition, Adipose tissue, Glucose metabolism, Fatty acid metabolism

\section{Introduction}

The increasing prevalence of obesity and its comorbidities is one of the major health problems in our modern world [1]. Although weight loss strategies target both sides of the energy balance, intake and expenditure, the success of long-term weight loss maintenance is low $[2,3]$. Adipose tissue is an important energy storing and releasing tissue and to fulfill this role

\footnotetext{
*Correspondence: sg.camps@maastrichtuniversity.nl

Department of Human Biology, Nutrition and Toxicology Research Institute

Maastricht, Maastricht University, PO Box 6166200 MD Maastricht, The
} Netherlands adipocytes need to respond quickly to variations in the demand. Many studies have linked obesity to metabolic processes on a whole-body level, like reduced fat oxidation, as well as inside the adipocyte like a reduced metabolism of long chain fatty acids [4-7]. Studies on weight loss indicate that energy restriction results in changes in the expression of genes involved in lipid, carbohydrate and energy metabolism in adipose tissue [8-13]. During energy restriction, the limiting glucose availability must be compensated by an increased mitochondrial fatty acid oxidation to 
preserve blood glucose levels and supply glucosedependent tissues with sufficient energy, such as the brain or red blood cells [14].

The biological response to weight loss is causing the susceptibility to weight regain as reviewed by MacLean et al. [15]. Mariman summarized this response as a network of adaptations with an energy gap promoting weight regain and physiological changes resulting in resistance for further weight loss [16]. Two of these adaptations are decreases in energy expenditure in response to energy restriction, which can limit weight loss and could be important factors that compromise the maintenance of a reduced body weight. Firstly, studies performed in lean and obese subjects have shown significant reductions in resting energy expenditure (REE) during and shortly after weight loss, to values below predictions based on weight loss and body composition changes [17-22]. The decrease in REE beyond what can be predicted by the loss of fat-free mass (FFM) and fat mass (FM) is defined as adaptive thermogenesis. Secondly, several studies demonstrated a decrease in physical activity and activity induced energy expenditure (AEE) as a result of weight loss [23-28].

Linking the physiological adaptations to the glucose and fatty acid metabolism will give further insight in the underlying metabolic responses. For this, changes in the levels of proteins involved in glucose and fatty acid metabolism were measured in adipose tissue before and after an 8-wk very low energy diet. Previously, Verhoef et al. showed results of such changes with parameters of adiposity during weight loss and maintenance [11]. Here, in the same subject population, the aim of the study was to determine whether such protein changes are associated with adaptations in energy expenditure. As target proteins, fructose-bisphosphate aldolase $\mathrm{C}$ (AldoC), short chain 3-hydroxyacyl-CoA dehydrogenase (HADHsc) and fatty acid binding protein 4 (FABP4) were chosen. In all participants of a weight lossmaintenance study, two isoforms of AldoC consistently decreased in abundance in the adipose tissue during energy restriction $[11,13]$. Although CPT1a is regarded to be the overall rate-limiting factor for mitochondrial uptake and oxidation of fatty acids, HADHsc has been shown to be involved in the ratelimiting acyl-CoA dehydrogenase step of betaoxidation [29]. This was later confirmed for oxidation of unsaturated fatty acids with odd-numbered double bonds [30]. In a weight loss-maintenance intervention, HADHsc was up-regulated in the adipose tissue of every participant due to energy restriction [12]. FABP4 is a general transporter of fatty acids in the adipocyte.

\section{Subjects and methods \\ Subjects}

Forty-eight healthy subjects (30 women and 18 men), mean $+\mathrm{SD}$ age of $42 \pm 8$ y and mean \pm SD body mass index (BMI) of $31.4 \pm 2.8 \mathrm{~kg} / \mathrm{m}^{2}$, were recruited by advertisements in local newspapers and on notice boards at the university. They underwent an initial screening that included measurement of body weight and height and the completion of a questionnaire on general health. All were in good health, not using medication (except for contraception), nonsmokers and at most moderate alcohol consumers. They were weight stable as defined by a weight change $<5 \mathrm{~kg}$ for at least 3 months prior to the study. The study was conducted according to the guidelines laid down in the Declaration of Helsinki and procedures were approved by the Ethics Committee of the Maastricht University Medical Centre. Written informed consent was obtained from all participants. This trial was registered at clinicaltrials.gov as NCT01015508.

\section{Study design}

The study covered an 8-wk period of a very low energy diet (VLED). Subjects came to the university for measurements on two occasions: the day before the start of the diet (baseline) and $8 \mathrm{wk}$ after the start of the diet (end of the diet). The protocol included an overnight stay at the university followed by the collection of blood, measurement of REE and body composition from 08.00 in the morning onwards in the fasting state. Two wk prior to each measurement day, subjects received a subject-specific dose of doubly labeled water to measure total energy expenditure (TEE) over the following 14 days.

\section{Diet}

The weight loss diet (Modifast; Nutrition et Santé Benelux, Breda, The Netherlands) was followed for a period of $8 \mathrm{wk}$. The diet was a protein-enriched formula that provided $2.1 \mathrm{MJ} /$ day (51.9 grams of protein, 50.2 grams of Carbohydrates and 6.9 grams of Lipids) and a micronutrient content, which meets the Dutch recommended daily allowance. The VLED was provided to the subjects as sachets with powder. Each sachet represented one meal and 3 sachets were consumed every day. In addition to the provided meal-replacements, subjects were allowed to eat vegetables when feeling hungry. Subjects were instructed to mix the powder with the amount of water indicated on the packages and were advised to drink water sufficiently throughout the diet period.

\section{Body composition}

Height was measured at screening to the nearest $0.1 \mathrm{~cm}$ with the use of a wall-mounted stadiometer (model 220; 
Seca, Hamburg, Germany). Body composition was determined according to Siri's three-compartment model based on body weight, body volume and total body water. Body weight was measured using a calibrated scale (Life Measurement Corporation, Inc, Concord, CA, USA). Body volume was measured via air-displacement plethysmography with the BodPod System (Life Measurement Corporation, Inc, Concord, CA, USA) [31, 32]. Total body water was determined using deuterium dilution during the preceding night, according to the Maastricht protocol [33]. BMI was calculated by dividing body weight by height squared $\left(\mathrm{kg} / \mathrm{m}^{2}\right)$.

\section{Resting energy expenditure}

At $0800 \mathrm{~h}$ in the morning, after the overnight stay at the university, subjects slowly walked to a separate room where they rested on a bed for $30 \mathrm{~min}$, followed by $30 \mathrm{~min}$ of measuring their REE in the supine position using an open-circuit ventilated hoodsystem [34]. Gas analyses were performed with a paramagnetic oxygen analyzer (Servomex, type 1158, Crowborough, East Sussex, UK) and an infrared carbon dioxide analyzer (Servomex, type 1520, Crowborough, East Sussex, UK) while flow was kept at a constant rate of $80 \mathrm{l} / \mathrm{min}$ and additionally measured as described by Schoffelen et al. [35]. The within individual coefficient of variation for this system is $3.3 \% \pm 2.1$ [34]. Calculation of REE from measured oxygen consumption and carbon dioxide production was based on Brouwer's formula [36].

In addition to measuring REE with the ventilated hood system (REEm), REE was predicted (REEp) with the equation: $\operatorname{REEp}(\mathrm{MJ} / \mathrm{d})=0.024 \mathrm{x}$ fat mass $(\mathrm{kg})+$ $0.102 \mathrm{x}$ fat free mass $\mathrm{x}(\mathrm{kg})+0.85$ [37]. Since fat mass (FM) and fat free mass (FFM) are used to calculate REEp, the equation can be used independently for gender. Adaptive thermogenesis was calculated as REEm divided by REEp [22].

\section{Total en activity induced energy expenditure}

Estimates of TEE were measured over two wk intervals with the doubly labeled water method according to the Maastricht protocol [33]. The doubly labeled water method is considered the gold standard for measuring TEE under field conditions [38]. On the evening of day 1 , shortly after the collection of a background urine sample, subjects drank a weighed amount of ${ }^{2} \mathrm{H}_{2}^{18} \mathrm{O}$ such that baseline levels were increased by 100-150 ppm for ${ }^{2} \mathrm{H}$ and $200-250 \mathrm{ppm}$ for ${ }^{18} \mathrm{O}$. Subsequently, urine samples were collected in the morning of day 2 (second voiding), day 8 and day 14 and in the evening of day 1, 8 and 13. The doubly labeled water method gives precise and accurate information on carbon dioxide $\left(\mathrm{CO}_{2}\right)$ production. $\mathrm{CO}_{2}$ production was subsequently converted to
TEE with the use of the energy equivalent of $\mathrm{CO}_{2}$, which can be calculated with additional information on the substrate mixture being oxidized [39]. The energy equivalent at baseline was calculated based on a normal Western diet with a mixed macronutrient composition and energy respectively for $55 \%$ from carbohydrate, $30 \%$ from fat and $15 \%$ from protein. At the end of the diet, the energy equivalent of $\mathrm{CO}_{2}$ was based on the consumption of the Modifast diet, the actual loss of fat mass and fat free mass and additional energy intake. The additional food intake was the calculated compensation for the difference between weight loss and the expected weight loss based on the consumption of the Modifast diet alone, with the assumption of $1 \mathrm{~kg}$ weight change to be equivalent to $30 \mathrm{MJ}$ [40]. The additional food intake was also assumed to be a normal mixed diet.

The indicated method to estimate AEE is the doubly labeled water method for the measurement of TEE in combination with a measurement of REE [41]. At baseline, AEE was calculated as (0.9 X TEE) - REE, assuming diet induced thermogenesis (DIT) to be $10 \%$ of TEE, which is based on a normal mixed diet [42] and DIT values for the separate macronutrients to be $10 \%$ for carbohydrate, $3 \%$ for fat and $25 \%$ for protein. At the end of the diet, the percentage DIT was calculated based on the intake of the Modifast diet and the additional food intake with a normal mixed composition, which accounted for the difference between the expected weight loss and the real weight loss. DIT was calculated to be $8 \%$ of the TEE at the end of the diet; therefore AEE was calculated as (0.92 X TEE) - REE.

\section{Western blot analysis}

Three proteins involved in glucose and fatty acid metabolisms were selected and measured in adipose tissue by Western blotting. Fructose-bisphosphate aldolase C (AldoC), fatty acid binding protein 4 (FABP4) and short chain 3-hydroxyacyl-CoA dehydrogenase (HADHsc).

Abdominal subcutaneous adipose tissue biopsies (approximately $1.5 \mathrm{~g}$ ) were obtained by needle liposuction under local anaesthesia (2\% lidocaine, Fresenius Kabi BV, The Netherlands) after an overnight fast, before and after the diet. Samples were rinsed in sterile cold saline, frozen in liquid nitrogen and stored at $-80{ }^{\circ} \mathrm{C}$ until protein isolation.

Frozen adipose tissue was grinded in a mortar and the powder was dissolved in $200 \mu$ of $8 \mathrm{M}$ urea, $2 \%$ CHAPS, $65 \mathrm{mM}$ DTT per $100 \mathrm{mg}$ powder. The homogenate was vortexed for $5 \mathrm{~min}$ and centrifuged for $30 \mathrm{~min}$ at $14000 \mathrm{rpm}$ and $10{ }^{\circ} \mathrm{C}$. The supernatant containing the adipose tissue proteome was carefully collected and aliquots were stored at $-80{ }^{\circ} \mathrm{C}$. Protein concentrations were determined by a Biorad Bradfortbased protein assay [43]. 
Samples with equal amount of protein were run on a $12 \%$ SDS polyacrylamide gel $(180 \mathrm{~V}$, Criterion Cell; Biorad, Hercules, CA) and then transferred $(90 \mathrm{~min}$, $100 \mathrm{~V}$, Criterion blotter; Biorad) to $0.45-\mathrm{mm}$ nitrocellulose membranes. After Ponceau S staining and destaining with demineralized water, membranes were blocked in $5 \%$ bovine serum albumin (BSA) in Tris-buffered saline containing $0.1 \%$ Tween 20 (TBST) for AldoC, and in $5 \%$ nonfat dry milk powder in TBST for FABP4 and HADHsc for $1 \mathrm{~h}$. Thereafter, the blots were incubated with the primary antibodies against AldoC (1:250 dilution, Santa Cruz sc-12066), FABP4 (1:1000 dilution, Cayman 10004944) and HADHsc (1:500 dilution, Santa Cruz sc-74650) in $5 \%$ BSA-TBST (AldoC) or $5 \%$ nonfat dry milk powder TBST (FABP4, HADHsc) overnight at $4{ }^{\circ} \mathrm{C}$ on a shaker. Thereafter, the blots were washed three times for $10 \mathrm{~min}$ in TBST, and then incubated with 1:10000 dilution of the horseradish peroxidase-conjugated secondary antibody (DAKO) in $5 \%$ BSA-TBST, $0.5 \%$ nonfat dry milk powder TBST or $5 \%$ nonfat dry milk powder TBST for $1 \mathrm{~h}$. The blots were washed three times for $10 \mathrm{~min}$ in TBST. A CCD camera (XRS-system, Biorad) was used to detect immunoreactive bands using chemiluminescent substrate (SuperSignal CL; Pierce). The quantification was performed with the program Quantity One version 4.6.5 (Biorad). Blots were normalized to beta-actin (1:1000 dilution, Santa Cruz sc-47778) to correct for differences in protein loading.

\section{Biochemical analysis}

Blood was collected into EDTA-containing tubes and centrifuged $\left(1000 \times \mathrm{g}, 10 \mathrm{~min}, 4^{\circ} \mathrm{C}\right)$, and the plasma was immediately frozen in liquid nitrogen and stored at $-80{ }^{\circ} \mathrm{C}$ until analysis. Plasma glucose concentration was analyzed enzymatically on a Cobas Mira automated spectrophotometer (Roche Diagnostica). Plasma insulin was measured with a double-antibody radioimmunoassay (Insulin RIA 100, Kabi-Pharmacia, Uppsala, Sweden).

\section{Calculations and statistical analysis}

A paired t-test (two-tailed distribution) was carried out to determine possible differences between mean values. Regression analysis and Spearman Rho's correlation coefficients were calculated for associations between parameters. One-way repeated measures ANOVA were used to compare the results across 0 and $8 \mathrm{wk}$, with gender as covariate. Significance was defined as $P<0.05$. The power calculation was based on a weight loss study, in which a significant 2-fold increase in HADHsc level was measured with Western blotting during weight loss in 8 obese subjects [12]. With an $\alpha$ of 0.05 , beta of 0.10 , mean change of 0.285 , and standard deviation of 0.223 for HADHsc, and taking into account an expected success-rate of $20 \%$ during weight maintenance and a dropout rate of $15 \%$, at least 29 subjects needed to be included at the start of the study. The data were analyzed using SPSS 20.0 (SPSS, Inc., Chicago, IL, USA). All data are presented as mean and standard deviation (SD).

\section{Results}

\section{Body composition}

After the $8 \mathrm{wk}$ of VLED, weight loss was on average 9.9 $\pm 4.1 \mathrm{~kg}(P<0.001)$ consisting of $7.9 \pm 3.3 \mathrm{~kg}$ of fat mass (FM) and $2.0 \pm 2.2 \mathrm{~kg}$ of fat free mass (FFM) (Table 1). Subjects lost on average $10.7 \pm 4.1 \%(P<0.001)$ of the starting weight. FM decreased from $41.8 \pm 6.3 \%$ to 37.3 $\pm 7.5 \%(P<0.001)$. The data showed a large interindividual variation in weight loss. The variation in weight loss was not explained by different levels of physical activity at baseline or $8 \mathrm{wk}$.

\section{Energy expenditure}

TEE decreased significantly from $12.65 \pm 2.08 \mathrm{MJ} / \mathrm{d}$ at baseline to $10.38 \pm 1.95 \mathrm{MJ} / \mathrm{d}(P<0.001)$ after the VLED; a decrease of $17.5 \pm 11.9 \%(P<0.001)$.

REE decreased significantly from $7.54 \pm 1.05 \mathrm{MJ} / \mathrm{d}$ at baseline to $6.70 \pm 0.87 \mathrm{MJ} / \mathrm{d}(P<0.001)$ after $8 \mathrm{wk}$ of VLED, which is a decrease of $10.8 \pm 6.6 \%(P<0.001)$. The decrease was explained by the reduced body weight and adaptive thermogenesis in response to the diet.

AEE decreased from $4.42 \pm 1.47 \mathrm{MJ} / \mathrm{d}$ at baseline to $3.27 \pm$ $1.24 \mathrm{MJ} / \mathrm{d}$ after $8 \mathrm{wk}$ of energy restriction $(P<0.001)$; a decrease of $22.8 \pm 28.7 \%(P<0.001)$ (Table 1$)$.

\section{Blood glucose}

Fasting glucose concentration at baseline was on average $4.9 \pm 0.5 \mathrm{mmol} / \mathrm{l}$ and was not different after weight loss $(4.8 \pm 0.6 \mathrm{mmol} / \mathrm{l})$.

Table 1 Subject characteristics (mean \pm SD) at baseline and after 8 wk on a very low energy diet

\begin{tabular}{lccc}
\hline & Pre-WL $(0 \mathrm{wk})$ & Post-WL $(8 \mathrm{wk})$ & P-value \\
\hline Weight $(\mathrm{kg})$ & $91.9 \pm 13.1$ & $82.0 \pm 11.2$ & $<0.001$ \\
BMl $\left(\mathrm{kg} / \mathrm{m}^{2}\right)$ & $31.4 \pm 2.8$ & $28.3 \pm 3.0$ & $<0.001$ \\
FM $(\mathrm{kg})$ & $36.3 \pm 7.3$ & $28.4 \pm 6.7$ & $<0.001$ \\
FFM $(\mathrm{kg})$ & $56.1 \pm 10.3$ & $54.0 \pm 9.5$ & $<0.001$ \\
TEE $(\mathrm{MJ} / \mathrm{d})$ & $12.65 \pm 2.08$ & $10.38 \pm 1.95$ & $<0.001$ \\
REE $(\mathrm{MJ} / \mathrm{d})$ & $7.52 \pm 0.98$ & $6.74 \pm 0.85$ & $<0.001$ \\
AEE $(\mathrm{MJ} / \mathrm{d})$ & $4.42 \pm 1.47$ & $3.27 \pm 1.24$ & $<0.001$ \\
Glucose $(\mathrm{mmol} / \mathrm{l})$ & $4.9 \pm 0.5$ & $4.8 \pm 0.6$ & 0.322 \\
\hline
\end{tabular}

$B M I$ body mass index, FM fat mass, FFM fat free mass, TEE total energy expenditure, $R E E$ resting energy expenditure, $A E E$ activity induced energy expenditure 


\section{Proteins}

Fatty acid binding protein 4 (FABP4) increased by $31.3 \pm 87.0 \%$ during VLED $(P<0.05)$. Fructosebisphosphate aldolase $C$ (AldoC) decreased significantly with $53.2 \pm 37.0 \%$ during the diet $(P<0.001)$. There was no significant change in short chain 3hydroxyacyl-CoA dehydrogenase (HADHsc) during the VLED-period (Fig. 1).

After $8 \mathrm{wk}$, the change in FABP4 was significant negatively correlated with the change in FM $(R=-0.35, P<$ $0.05)$, while the change in AldoC was significant positively correlated with the change in FFM $(R=0.52, P<0.001)$ (Table 2).

After weight loss, there was a significant positive correlation between the change in AldoC and the percentage change in TEE $(R=0.44, P<0.01)$; more specifically there was a significant positive correlation between the change in AldoC and the percentage change in $\operatorname{AEE}(R=0.44, P<$ 0.01 ). Furthermore, there was a significant positive correlation between the change in HADHsc and adaptive thermogenesis in REE after the VLED $(R=0.34, P<0.05)$.

After $8 \mathrm{wk}$, there were positive correlations between the changes in FABP4 and HADHsc $(R=0.38, P<0.05)$, between FABP4 and AldoC $(R=0.47, P<0.01)$ and HADHsc and AldoC $(R=0.46, P<0.01)$ (Table 2$)$.

\section{Discussion}

Measuring proteins involved in glucose and fatty acid metabolism before and after an 8-wk VLED reflects the
Table 2 Spearman Rho's correlation coefficients of changes in protein levels with changes in body composition and energy expenditure parameters. Increased (+) and decreased (-) parameters are indicated in the first column

\begin{tabular}{llll}
\hline & FABP4 & HADHsc & AldoC \\
\hline FABP4 (+) & & $0.38^{*}$ & $0.47^{* *}$ \\
HADHsc & $0.38^{*}$ & & $0.46^{* *}$ \\
AldoC (-) & $0.47^{* *}$ & $0.46^{* *}$ & \\
FM (-) & $-0.35^{*}$ & & \\
FFM (-) & & & $0.52^{* * *}$ \\
REE (-) & & $0.34^{*}$ & \\
AEE $(-)$ & & $0.44^{*}$ \\
TEE $(-)$ & & & $0.44^{*}$ \\
\hline
\end{tabular}

${ }^{*} P<0.05,{ }^{* *} P<0.01,{ }^{* * *} P<0.001, F A B P 4$ fatty acid binding protein $4, H A D H s C$ short chain 3-hydroxyacyl-CoA dehydrogenase, AldoC fructose-bisphosphate aldolase $C$, FM fat mass, FFM fat free mass, REE resting energy expenditure, $A E E$ activity induced energy expenditure, TEE total energy expenditure

metabolic adaptations occurring in adipose tissue linked to energy expenditure. More specifically, the decrease of AldoC, an enzyme of glycolysis, is correlated with the decrease in AEE, and the non-significant change HADHsc, a crucial enzyme for mitochondrial betaoxidation, is negatively correlated with the adaptation in REE. Furthermore, there is a correlation between the increase in FABP4, the intracellular fatty acid transporter, and the decrease in fat mass, and a correlation between the decrease in AldoC and the decrease in fat free mass. FABP4, AldoC and HADHsc are all positively correlated.

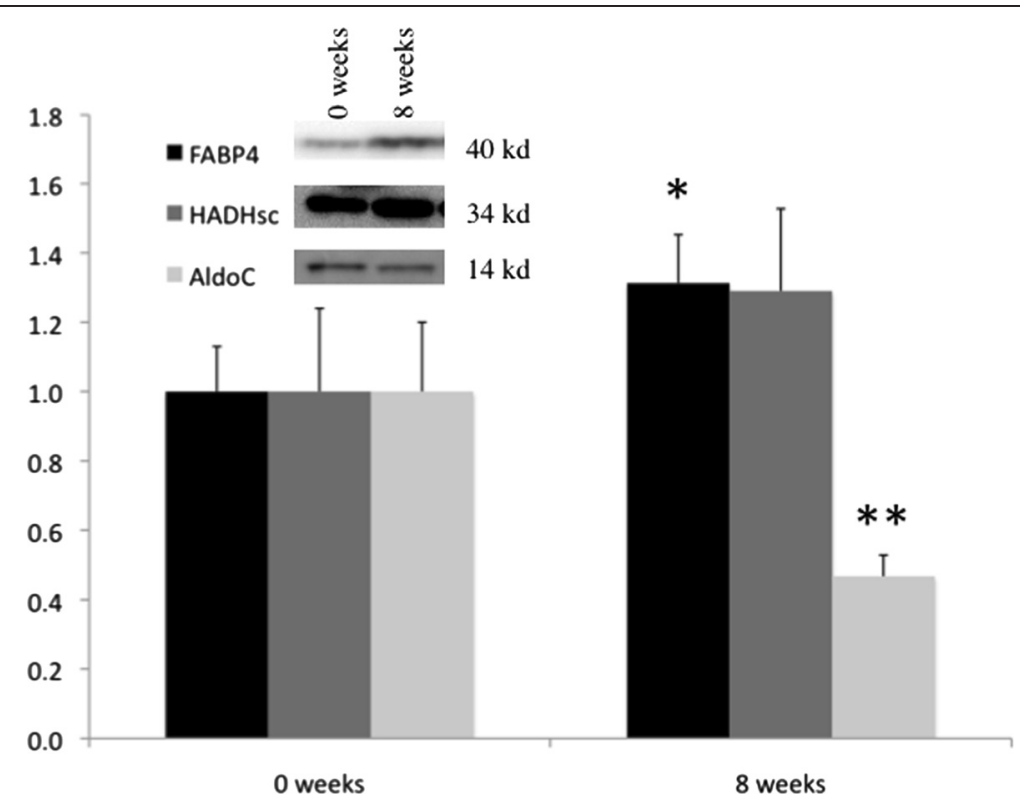

Fig. 1 Fold changes of post-WL ( 8 wk) compared to pre-WL $(0 \mathrm{wk})$. Fold changes are obtained by dividing the average spot intensity of the post-WL group by that of the pre-WL group. Protein levels of FABP4, HADHsc and AldoC were analyzed using Western blotting. Representative results of 3 independent experiments are shown; Beta-actin was used as an internal control to ensure equal loading in all lanes of the gel (results not shown). ${ }^{*} P<0.05,{ }^{*} P<0.001$, FABP4, Fatty acid binding protein 4, HADHsc, Short chain 3-hydroxyacyl-CoA dehydrogenase, AldoC, Fructose-bisphosphate aldolase C 
The increased FABP4 after the VLED weight loss is in accordance with previous results in obese subjects $[11,12,44]$. It is in line with an elevation in intracellular trafficking of fatty acids, which is expected during a negative energy balance when lipolysis is stimulated, with the release of fatty acids from stored triglycerides that can then be used for the mitochondrial beta-oxidation within the fat cell or be secreted from the cell to serve as energy source for other tissues. During conditions of energy restriction, an increase of the lipolysis, and intracellular trafficking of fatty acids, results in a decrease in fat mass. This would be in line with the observed correlation between increase of FABP4 and loss of fat mass.

The decreased AldoC during energy restriction is in accordance with previous results in obese subjects on an energy-restricted diet $[11,12]$. Concurrently, blood glucose is not changed after energy restriction. The consistently observed decrease in AldoC during energy restriction [13], suggests that it may be a marker for the glycolytic flux in fat tissue. In addition, a parallel between a decrease of glycolytic flux in fat tissue on one hand and a decrease in activity and muscle use on the other hand, may underlie the observed correlation between the decrease in AldoC and the decrease in AEE. The decrease in AEE is in line with previous studies that show a reduction in physical activity following energy restriction [23-28]. Hypothetically, our results could indicate that during reduced glucose availability as a substrate, there is decreased glycolytic flux in fat tissue and decreased activity in order to preserve blood glucose as a supply for glucose-dependent tissues, such as the brain or red blood cells [45]. Additionally, reduced substrate availability may increase the demand for amino acids as an energy source for other tissues [46]. This would be in keeping with the observed correlation between the decrease in AldoC and the decrease in fat free mass.

HADHsc is not significantly increased at the end of the 8-wk VLED, which has been described before [11, 12]. Previously, Bouwman et al. showed a positive correlation between three enzymes of the beta-oxidation (HADHsc, Acetyl-CoA acetyltransferase and Acyl-CoA dehydrogenase) and plasma free fatty acids (FFA) during weight loss maintenance [13]. Apparently, the adipose tissue level of HADHsc parallels the level of plasma FFA. An increased level of FFA during energy restriction would support the energy flux to other peripheral tissues, which could allow lower adaptative thermogenesis in REE. This seems to be in line with the observed correlation between the change in HADHsc and adaptive thermogenesis after the 8-wk VLED. HADHsc is crucial for beta-oxidation [29, 30]. Therefore, it is possible that changes in HADHsc reflect changes in the flux of fatty acids through the mitochondrial beta-oxidation pathway. Hypothetically, upregulation of the mitochondrial beta-oxidation flux might be the consequence of an activated lipolysis, leading to increased plasma FFA and smaller adaptive thermogenesis in REE.

The correlation between FABP4 and HADHsc would also be in line with the HADHsc level reflecting the lipolytic activity, because this would parallel the requirement for intracellular trafficking of fatty acids. Additionally, an increased trafficking and beta-oxidation of fatty acids in

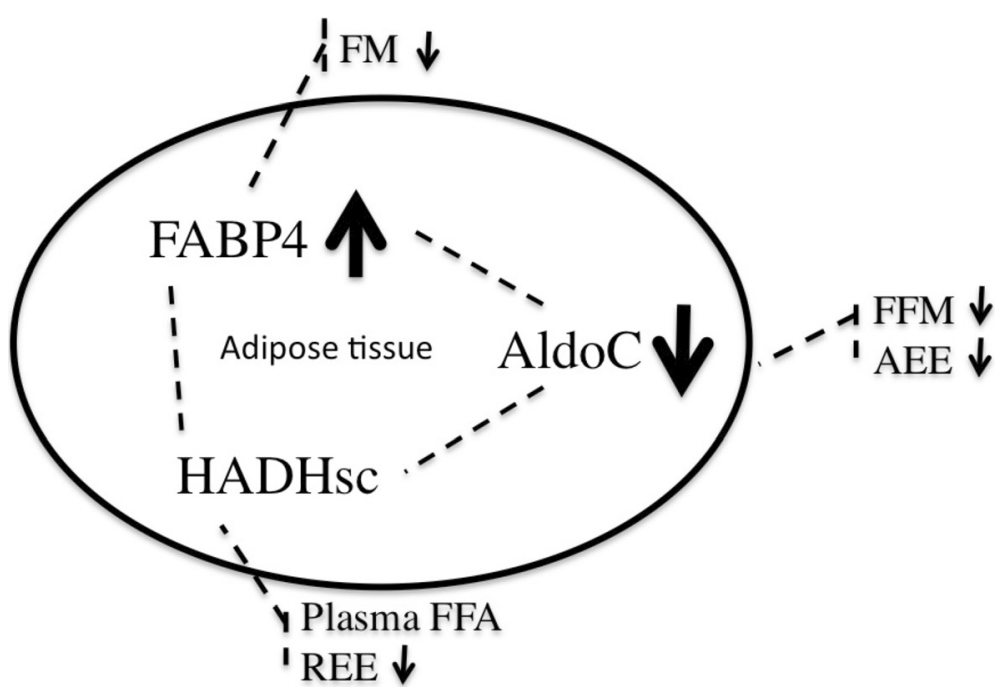

Fig. 2 Overview of the network of changes inside the adipose tissue as a result of a negative energy balance and the hypothetical connections with adaptations in body composition and energy expenditure. FABP4, Fatty acid binding protein 4, HADHsc, Short chain 3-hydroxyacyl-CoA dehydrogenase, AldoC, Fructose-bisphosphate aldolase C, FM, fat mass, FFM, fat free mass, FFA, free fatty acids, REE, resting energy expenditure, AEE, activity induced energy expenditure, TEE, total energy expenditure 
the adipose tissue might coincide with a reduced flux through the glycolytic pathway. In this respect, a positive correlation between AldoC and FABP4 and HADHsc would imply that higher fatty acid flux is better for maintenance of glycolytic flux.

A limitation of this study is the use of total adipose tissue biopsy material for Western blotting, because this could have contained other cell types in the stromal vascular fraction. However, the findings of our previous studies indicate that the majority of the isolated protein is derived from adipocytes [13]. Furthermore, beta-actin showed no significant changes and was chosen as a housekeeping control to be able to compare the present results with those of other studies. Although the selected proteins are involved in the major steps of the glucose and fatty acid metabolism and may reflect the capacity of metabolic pathways, it should be noted that protein levels do not represent the actual flux through the pathways. Furthermore, the observed correlations of the adipose tissues cannot be translated into regulatory mechanisms and are not suited to prove causation. Though, the observed outcomes are consistent with intuitive expectations and the hypothesized mechanisms could be subject of future research.

In conclusion, during energy restriction, the molecular metabolism in adipose tissue is linked to energy expenditure. More specifically, the decrease in AldoC is correlated to the decrease in AEE, which could be explained by the preservation of glucose, and the change in HADHsc is correlated to adaptive thermogensis in REE, which could be explained by changes in the beta-oxidation and lipolysis. Overall, our findings reveal a link between changes on a physiological level and changes of the molecular metabolism in fat cells. This shows the important role of adipose tissue in obese people. The molecular changes in adipose tissue as a result of a negative energy balance might even be the underlying driver of adaptations in body composition and energy expenditure (Fig. 2).

\section{Competing interests}

The authors have nothing to disclose.

\section{Authors' contributions}

K.R. Westerterp and S.P.M. Verhoef designed the study. S.G.J.A. Camps and S.P.M. Verhoef collected the data. S.G.J.A. Camps, S.P.M. Verhoef, N. Roumans and F.G. Bouwman analyzed the data. S.G.J.A. Camps, wrote the manuscript. K.R. Westerterp and E.M. Mariman contributed to the interpretation of the data and reviewed the manuscript. The study was executed under supervision of K.R. Westerterp. All authors read and approved the final manuscript.

\section{Funding}

Funded by Maastricht University.
Received: 21 January 2015 Accepted: 19 October 2015

Published online: 24 October 2015

\section{References}

1. Catenacci VA, Hill JO, Wyatt HR. The obesity epidemic. Clin Chest Med. 2009;30:415-44. vii.

2. Kraschnewski JL, Boan J, Esposito J, Sherwood NE, Lehman EB, Kephart DK, et al. Long-term weight loss maintenance in the United States. Int J Obes (Lond). 2010;34:1644-54

3. Wing RR, Phelan S. Long-term weight loss maintenance. Am J Clin Nutr. 2005:82:222S-5S

4. Blaak EE, Hul G, Verdich C, Stich V, Martinez A, Petersen M, et al. Fat oxidation before and after a high fat load in the obese insulin-resistant state. J Clin Endocrinol Metab. 2006;91:1462-9.

5. Frisancho AR. Reduced rate of fat oxidation: a metabolic pathway to obesity in the developing nations. Am J Hum Biol. 2003;15:522-32.

6. Westerterp KR, Smeets A, Lejeune MP, Wouters-Adriaens MP, Westerterp-Plantenga MS. Dietary fat oxidation as a function of body fat. Am J Clin Nutr. 2008;87:132-5.

7. Walewski JL, Ge F, Gagner M, Inabnet WB, Pomp A, Branch AD, et al. Adipocyte accumulation of long-chain fatty acids in obesity is multifactorial, resulting from increased fatty acid uptake and decreased activity of genes involved in fat utilization. Obes Surg. 2010;20:93-107.

8. Speakman JR, Mitchell SE. Caloric restriction. Mol Aspects Med. 2011;32:159-221.

9. Capel F, Viguerie N, Vega N, Dejean S, Arner P, Klimcakova E, et al. Contribution of energy restriction and macronutrient composition to changes in adipose tissue gene expression during dietary weight-loss programs in obese women. J Clin Endocrinol Metab. 2008;93:4315-22.

10. Johansson LE, Danielsson AP, Parikh H, Klintenberg M, Norström F, Groop L, et al. Differential gene expression in adipose tissue from obese human subjects during weight loss and weight maintenance. Am J Clin Nutr. 2012;96:196-207

11. Verhoef SP, Camps SG, Bouwman FG, Mariman EC, Westerterp KR. Physiological response of adipocytes to weight loss and maintenance. PLoS One. 2013;8:e58011.

12. Bouwman FG, Wang $P$, van Baak M, Saris WH, Mariman EC. Increased betaoxidation with improved glucose uptake capacity in adipose tissue from obese after weight loss and maintenance. Obesity (Silver Spring). 2014;22:819-27.

13. Bouwman FG, Claessens M, van Baak MA, Noben JP, Wang P, Saris WH, et al. The physiologic effects of caloric restriction are reflected in the in vivo adipocyte-enriched proteome of overweight/obese subjects. J Proteome Res. 2009;8:5532-40.

14. Cahill Jr GF, Herrera MG, Morgan AP, Soeldner JS, Steinke J, Levy PL, et al. Hormone-fuel interrelationships during fasting. J Clin Invest. 1966;45:1751-69.

15. Maclean PS, Bergouignan A, Cornier MA, Jackman MR. Biology's response to dieting: the impetus for weight regain. Am J Physiol Regul Integr Comp Physiol. 2011;301:R581-600.

16. Mariman EC. Human biology of weight maintenance after weight loss. J Nutrigenet Nutrigenomics. 2012;5:13-25.

17. Leibel RL, Rosenbaum M, Hirsch J. Changes in energy expenditure resulting from altered body weight. N Engl J Med. 1995;332:621-8.

18. Dulloo AG, Jacquet J. Adaptive reduction in basal metabolic rate in response to food deprivation in humans: a role for feedback signals from fat stores. Am J Clin Nutr. 1998;68:599-606.

19. Schwartz A, Doucet E. Relative changes in resting energy expenditure during weight loss: a systematic review. Obes Rev. 2010;11:531-47.

20. Tremblay A, Chaput JP. Adaptive reduction in thermogenesis and resistance to lose fat in obese men. Br J Nutr. 2009;102:488-92.

21. Weyer C, Walford RL, Harper IT, Milner M, MacCallum T, Tataranni PA, et al. Energy metabolism after 2 y of energy restriction: the biosphere 2 experiment. Am J Clin Nutr. 2000;72:946-53.

22. Camps SG, Verhoef SP, Westerterp KR. Weight loss, weight maintenance, and adaptive thermogenesis. Am J Clin Nutr. 2013;97:990-4.

23. de Groot LC, van Es AJ, van Raaij JM, Vogt JE, Hautvast JG. Adaptation of energy metabolism of overweight women to alternating and continuous low energy intake. Am J Clin Nutr. 1989;50:1314-23.

24. Martin CK, Heilbronn LK, de Jonge L, DeLany JP, Volaufova J, Anton SD et al. Effect of calorie restriction on resting metabolic rate and spontaneous physical activity. Obesity (Silver Spring). 2007;15:2964-73. 
25. Redman LM, Heilbronn LK, Martin CK, et al. Metabolic and behavioral compensations in response to caloric restriction: implications for the maintenance of weight loss. PLoS One. 2009;4, e4377.

26. Bonomi AG, Soenen S, Goris AH, Westerterp KR. Weight-loss induced changes in physical activity and activity energy expenditure in overweight and obese subjects before and after energy restriction. PLoS One. 2013;8:e59641.

27. Martin CK, Das SK, Lindblad L, Racette SB, McCrory MA, Weiss EP, et al. Effect of calorie restriction on the free-living physical activity levels of nonobese humans: results of three randomized trials. J Appl Physiol (1985). 2011;110:956-63.

28. Camps SG, Verhoef SP, Westerterp KR. Weight loss-induced reduction in physical activity recovers during weight maintenance. Am J Clin Nutr. 2013;98:917-23.

29. Kler RS, Jackson S, Bartlett K, Bindoff LA, Eaton S, Pourfarzam M, et al. Quantitation of acyl-CoA and acylcarnitine esters accumulated during abnormal mitochondrial fatty acid oxidation. J Biol Chem. 1991;266:22932-8.

30. Shoukry K, Schulz H. Significance of the reductase-dependent pathway for the beta-oxidation of unsaturated fatty acids with odd-numbered double bonds. Mitochondrial metabolism of 2-trans-5-cis-octadienoyl-CoA. J Biol Chem. 1998;273:6892-9.

31. Ginde SR, Geliebter A, Rubiano F, Silva AM, Wang J, Heshka S, et al. Air displacement plethysmography: validation in overweight and obese subjects. Obes Res. 2005;13:1232-7.

32. Dempster $P$, Aitkens S. A new air displacement method for the determination of human body composition. Med Sci Sports Exerc. 1995;27:1692-7.

33. Westerterp KR, Wouters L, van Marken Lichtenbelt WD. The Maastricht protocol for the measurement of body composition and energy expenditure with labeled water. Obes Res. 1995;3 Suppl 1:49-57.

34. Adriaens MP, Schoffelen PF, Westerterp KR. Intra-individual variation of basal metabolic rate and the influence of daily habitual physical activity before testing. Br J Nutr. 2003:90:419-23.

35. Schoffelen PF, Westerterp KR, Saris WH, Ten Hoor F. A dual-respiration chamber system with automated calibration. J Appl Physiol. 1997:83:2064-72.

36. Brouwer E. On simple formulae for calculating the heat expenditure and the quantities of carbohydrate and fat oxidized in metabolism of men and animals, from gaseous exchange (Oxygen intake and carbonic acid output) and urine-N. Acta Physiol Pharmacol Neerl. 1957;6:795-802.

37. Westerterp KR, Donkers JH, Fredrix EW, Boekhoudt P. Energy intake, physical activity and body weight: a simulation model. Br J Nutr. 1995;73:337-47.

38. Shephard RJ, Aoyagi Y. Measurement of human energy expenditure, with particular reference to field studies: an historical perspective. Eur J Appl Physiol. 2012:112:2785-815.

39. Black A, Prentice A, Coward W. Use of food quotients to predict respiratory quotients for the doubly-labelled water method of measuring energy expenditure. Human nutrition. Clinical nutrition. 1986;40:381-91.

40. Westerterp KR. Physical activity, food intake, and body weight regulation: insights from doubly labeled water studies. Nutr Rev. 2010;68:148-54.

41. Westerterp KR. Daily physical activity as determined by age, body mass and energy balance. Eur J Appl Physiol. 2015;115:1177-84

42. Westerterp KR. Impacts of vigorous and non-vigorous activity on daily energy expenditure. Proc Nutr Soc. 2003;62:645-50.

43. Bradford MM. A rapid and sensitive method for the quantitation of microgram quantities of protein utilizing the principle of protein-dye binding. Anal Biochem. 1976;72:248-54.

44. Fritzen AM, Lundsgaard AM, Jordy AB, Poulsen SK, Stender S, Pilegaard $H$, et al. New Nordic Diet induced weight loss is accompanied by changes in metabolism and AMPK signalling in adipose tissue. J Clin Endocrinol Metab. 2015;100:jc20152079

45. Canto C, Jiang LQ, Deshmukh AS, Mataki C, Coste A, Lagouge M, et al. Interdependence of AMPK and SIRT1 for metabolic adaptation to fasting and exercise in skeletal muscle. Cell Metab. 2010;11:213-9.

46. Villareal DT, Smith GI, Shah K, Mittendorfer B. Effect of weight loss on the rate of muscle protein synthesis during fasted and fed conditions in obese older adults. Obesity (Silver Spring). 2011:20:1780-6.

\section{Submit your next manuscript to BioMed Central and take full advantage of:}

- Convenient online submission

- Thorough peer review

- No space constraints or color figure charges

- Immediate publication on acceptance

- Inclusion in PubMed, CAS, Scopus and Google Scholar

- Research which is freely available for redistribution

Submit your manuscript at www.biomedcentral.com/submit 